\title{
A Computer-Aided Design Method Course to Improve Students’ Design Skills
}

\author{
Qingli (Barbara) Dai, Ph.D. \\ Research Assistant Professor \\ Department of Mechanical Engineering- Engineering Mechanics \\ Michigan Technological University \\ qingdai@mtu.edu
}

\begin{abstract}
NX Unigraphics is a key CAD/CAM/CAE software used in the mechanical engineering curriculum of Michigan Technological University (MTU). The elective Computer-Aided Design (CAD) Method course instructs students in both practical and theoretical aspects of using computers to aid in the design of mechanical systems. Computer-Assisted Self Teaching (CAST) tutorials were effectively used to learn NX. Specific parts of each tutorial are assigned for learning the solid modeling skills. The design projects built the skills of what has been learned in tutorial assignments by modeling real mechanical systems.

MTU hosted the Partners for the Advancement of Collaborative Engineering Education (PACE) Competition in CAD Methods class (MEEM 4403). The course final deign project that comprises the team competition is the culmination of lab assignments performed throughout the semester. Each team made a formal presentation to the PACE judges to explain the design objectives, design features, features of the CAD model, and any issues related to working collaboratively on a team. The design itself was presented using screen captures and/or animation. Each team was evaluated on their ability to do parametric modeling, motion simulation, team work and effective presentations. Students were excited with PACE Competition by presenting their group achievements and their $\mathrm{CAD}$ abilities to the judges and other classmates. This competition event also encouraged them to pursue a career of mechanical design and manufacture in industries.

Background

Michigan Technological University's Department of Mechanical EngineeringEngineering Mechanics (ME-EM) was selected to be partnership with General Motors, EDS, and Sun Microsystems in the PACE program for the Advancement of CAD/CAM/CAE Education on August 30, 2000. The PACE program's mission is to integrate mathematics-based CAD/CAM/CAE (Unigraphics NX) into the curriculum of strategically selected academic partners worldwide. Michigan Tech was one of only two U.S. universities selected for the initial four academic program partner sites.
\end{abstract}


Today NX is the key CAD/CAM/CAE software used in our mechanical engineering curriculum and utilized in our laboratories [1]. It is integrated throughout our curriculum beginning with the first year, to learn solid modeling using NX. Sophomore students use NX in the lab portion of the course "Integrated Design and Manufacturing" to create the tool paths to produce a designed part. Junior students use NX in the Product Realization I and II courses. Senior students use NX in their capstone senior design project sequence, and can also practice NX by taking technical electives in CAD and Finite Element Analysis.

Elective course MEEM 4403 - Computer-Aided Design (CAD) Method [2] is to help students practice the computer - aided design of mechanical system though theoretical lectures and laboratory assignments. NX integrated with this CAD method course allowed students to learn the modern industrial design skills. PACE competition based on the course final design projects judged the students' teamwork from professional aspects.

\section{Objective of the Course and Activities}

The objectives of this elective course are to instruct students in both practical and theoretical aspects of using computers to aid in the design of mechanical systems. The course covers practical topics such as solid modeling (basic to intermediate, with some advanced surfacing), assembly modeling (using both bottom-up and parametric top-down techniques), collaborative designing in teams, and motion simulation. Theoretical concepts that were taught include solid modeling, data structures, sketch constraints, and parametric curves and surfaces. Overviews of ancillary topics are also given such as tolerancing, manufacturing, and optimization. CAD, CAM, and CAE are obviously integral to the course [3]. The course has six lab projects, which build on each other. Three of them are team projects. Students are also given two written exams and one laboratory exam to test their modeling ability.

\section{Identification of Concepts in Course Study}

Although students are required to learn basic Computer-Aided Design methods in the freshman year of Engineering, students come with a variety of abilities due to having learned different design software, transferring in from another university, or minimal use of CAD. Therefore, this course starts from the beginning, but proceeds at a rapid rate. To learn NX we use the Computer-Assisted Self Teaching (CAST) tutorials as much as possible, however, the extreme depth and completeness of the tutorials and the limited time for the course makes it impossible for students to go through the tutorials sequentially. Instead, specific parts of each tutorial are assigned and students can refer to the skipped parts of the tutorial if they come across a difficult situation. A specific NX textbook is also suggested for students who want to work sequentially. Each of the six lab assignments in the course comprises one project, three of which are done in teams. The ME-EM department of Michigan Tech hosted PACE competition with this course. The team competition, based on the final deign project, is the culmination of lab assignments performed throughout the semester 


\section{Design Projects}

To accomplish the objectives of using computers to aid in the design of mechanical systems, the course covers practical topics such as solid modeling (basic to intermediate, with some advanced surfacing), assembly modeling (using both bottom-up and parametric top-down techniques), collaborative designing in teams, motion simulation. The design projects were assigned to cover these topics consequently:

1. Reverse engineering of an existing part.

2. Use engineering equations to model a component parametrically.

3. Use bottom-up assembly modeling in a team.

4. Model the outside shape of a product with styled surfaces.

5. Use advanced parametric top-down product modeling techniques in a team.

6. Simulate the motion of the team-designed product.

Each project built is based on what has been learned in previous assignments. The final project is presented to judges from PACE companies in a culminating PACE competition. Figure 1 shows the results from some projects. 


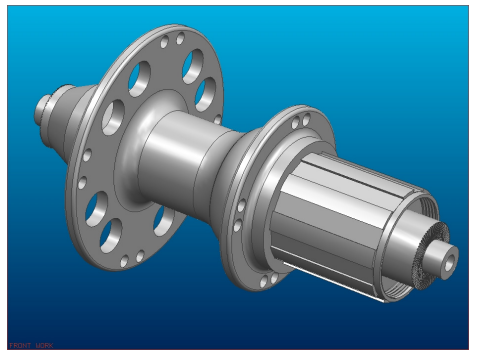

(a)

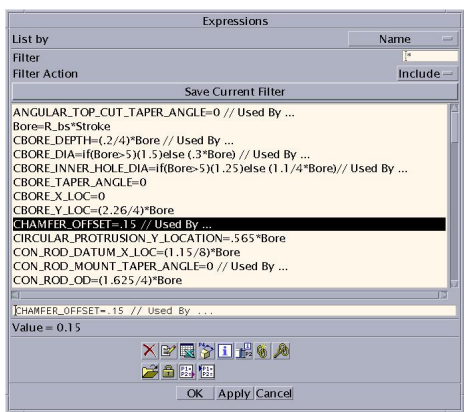

K Apply Cancel

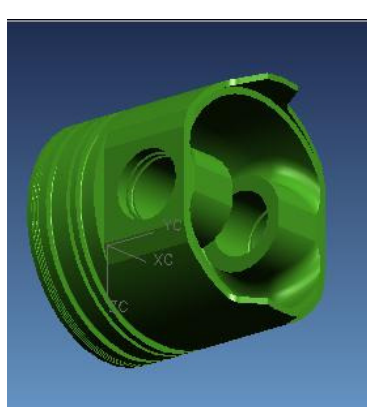

(b)

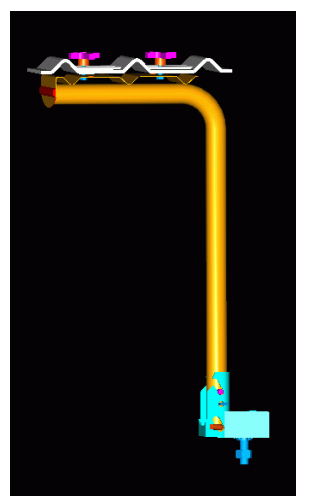

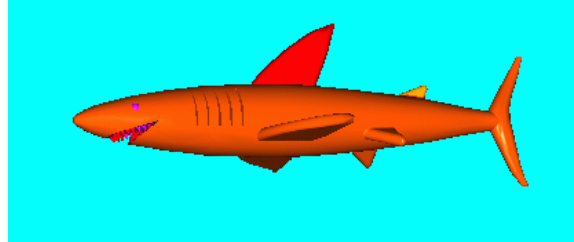

(c)
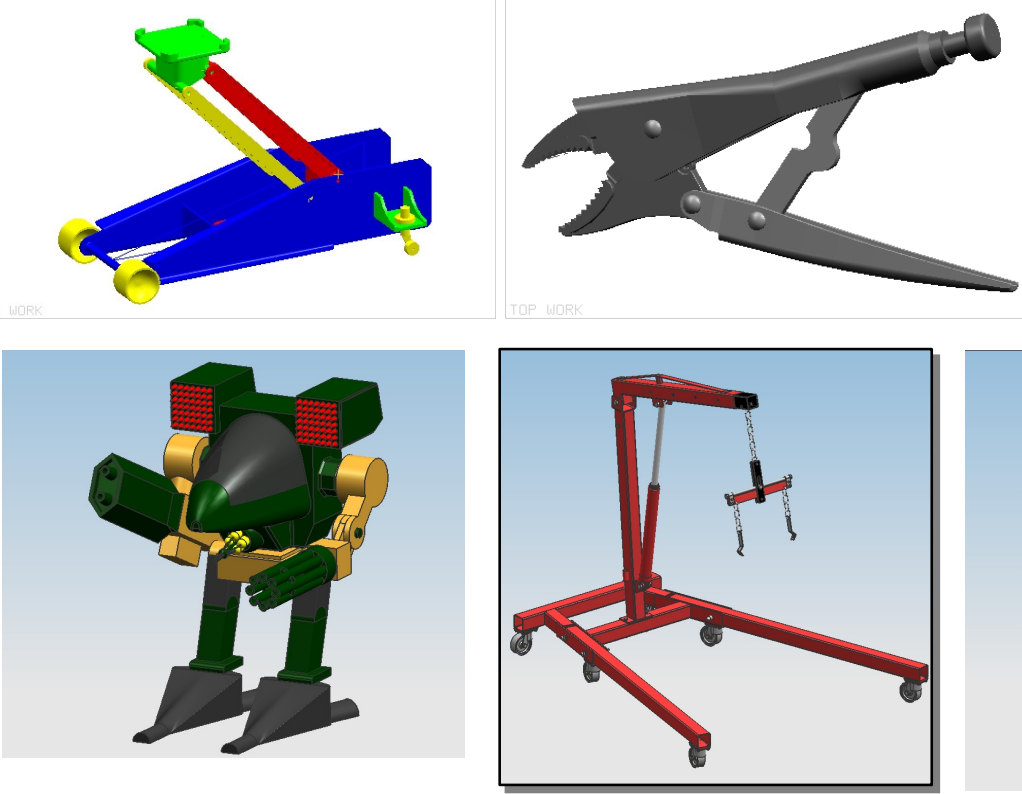

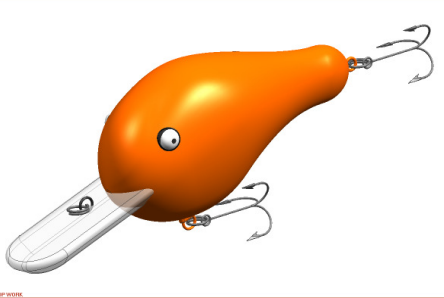

(d)

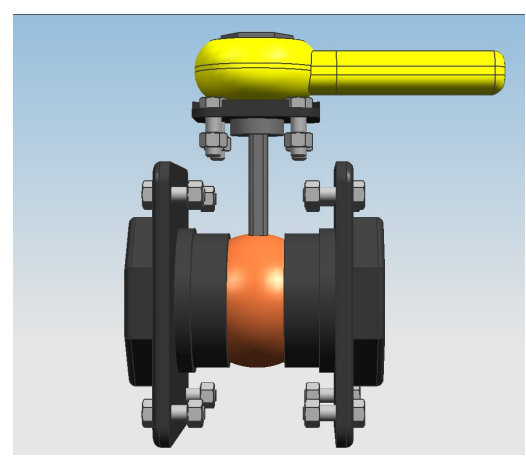

(e)

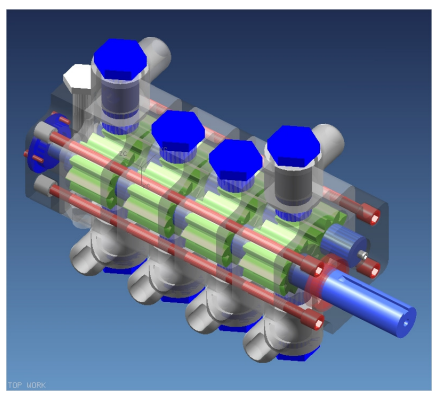


Figure 1. Some student projects from the CAD Methods course (a) reverse engineering, (b) parametric modeling (c) bottom-up assembly modeling (d) freeform shape modeling (e) parametric top-down product modeling and motion simulation

\section{PACE Competition}

The PACE Program links GM, EDS, Sun Microsystems, and UGS in support of strategically-selected academic institutions worldwide that help to develop future products and encourage students to be manufacturing engineers, designers, and managers who can understand and apply parametrics-based applications in the automotive life cycle management process. As part of its commitment to encourage students to use digital data in the product development and analysis processes, PACE is providing student design competitions in appropriate courses within PACE Institution curricula.

PACE competition judged four critical areas of the virtual product development process:

1. Parametric Modeling

2. Computer Aided Engineering (CAE) Simulation

3. Aesthetics and Presentation

4. Teamwork and collaboration

Michigan Technological University hosted the PACE Competition in its MEEM 4403 Computer-Aided Design Methods class in fall 2006 [4]. The competition was a team competition. The team competition was based on the final lab assignment: collaborative design and simulation of a mechanism.

The project that comprises this team competition is the culmination of lab assignments performed throughout the semester [5]. This includes solid modeling, parametric modeling, assembly modeling, freeform surface modeling, top-down design using master models, and kinematic simulation. Each team made a very short (four-minute) formal presentation to the PACE judges to explain the design objectives, design features, features of the CAD model, and any issues related to working collaboratively on a team. The design itself was presented using screen captures and/or animation. Teams discussed their use of parametric modeling techniques, and demonstrated the motion analysis with reference to animations and/or graphs. Each team was evaluated on their ability to do parametric modeling, motion simulation, team work and effective presentations. Students were also excited with PACE Competition by presenting their group achievements and their CAD abilities to the judges and other classmates. This competition event also encourages them to pursue a career of mechanical design and test in industries. Figure 2 shows the pictures of awarded team projects in Fall 2006 PACE competition. It should be mentioned that the first award was received by a team composed by three female-students. 


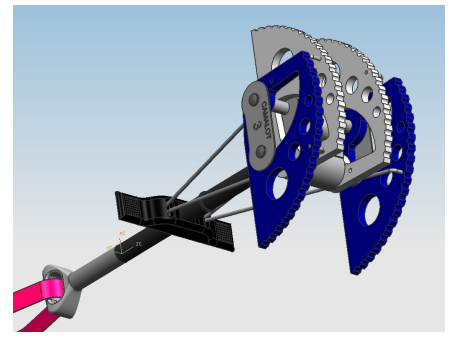

(a)

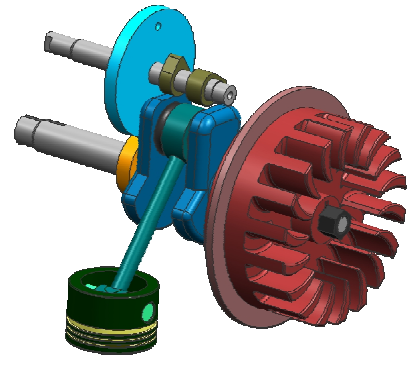

(b)

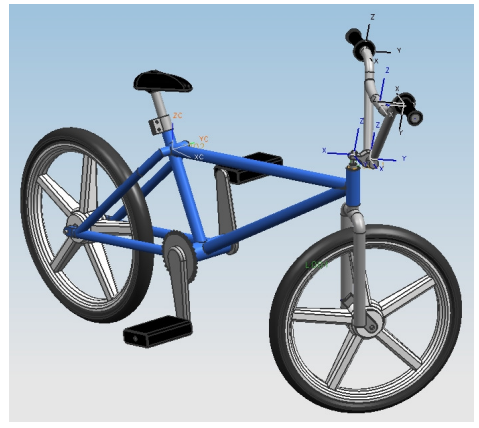

(c)

Figure 2. Awarded design projects in PACE Competition (Fall 2006, Computer-Aided Design Methods) (a) Rock Climbing Cam (b) Snow Blower Crankshaft (c) BMX Bicycle.

The students had a positive response to the PACE competitions. Generally, there was an initial trepidation because of adding an additional big assignment to an already full schedule; however, the competition was integrated into the course so that it does not add too much excessive workload. The students were very pleased to be recognized for their work, and receive feedback from professionals.

\section{Summary}

In this paper, the author presented CAD methods course integrated with PACE Competition by using NX software. This elective course is to help senior students use world-class software to design mechanical systems. The course covered a series of topics on computer-aided design techniques. The computer design projects were assigned to practice these topics. These design skills also benefits the senior design projects. Throughout the diverse course of lectures, exams, projects, and PACE competition, students learned different design skills, practiced teamwork, and also presented their design projects in a professional manner.

NX was used in the entire curriculum of ME-EM department. One of the most significant benefits is that students have world-class software that allows them to easily work on $\mathrm{CAD} / \mathrm{CAM} / \mathrm{CAE}$ engineering throughout the Mechanical Engineering curriculum. This software allows them to build on what they learned in earlier courses and apply it in later courses.

\section{References}

1. Unigraphics NX 3, UGS Corp, http://www.ugs.com/products/nx/.

2. MEEM 4403: Computer-Aided Design Methods (Unigraphics NX3) http://www.me.mtu.edu/courses/meem4403/MEEM4403_Fa_06/

3. Michigan Technological University PACE Design Competition in MEEM 4403 Computer-Aided Design Methods, Competition Outline, 2006. 
4. PACE Engineering Design Competition, http://www.me.mtu.edu/pace/pace_contest_Dec_2006.htm

5. Kunwoo Lee, Principles of CAD/CAM/CAE Systems, Addison Wesley Longman, Inc, 1999.

\section{Biography}

Qingli Dai received her Ph.D degree from mechanical engineering and applied mechanics of university of Rhode Island in 2004. She worked as visiting assistant professor in Mechanical engineering of Texas A\& M University-Kingsville in 2005. Currently, she is a research assistant professor and visiting assistant professor of the Department of Mechanical Engineering- Engineering Mechanics at Michigan Technological University. She has taught CAD methods, statics, introduction to finite element methods, computeraided analysis, and other courses. She has published over 25 journal and conference publications in the past a few years. 